Sallyann T. Colbert FFA RCSI, Emer Curran FFA RCSI, Deirdre M. O'Hanlon FrCSI, * Ray Moran FRCSI, * Maire McCarroll FFA RCSI

\section{Intra-articular tenoxicam improves postoperative analgesia in knee arthroscopy}

Purpose: Non Steroidal Anti-Inflammatory drugs have a well documented benefit in the relief of postoperative pain. This study was designed to compare the analgesic effect of intra-articular tenoxicam $20 \mathrm{mg}$ with intravenous tenoxicam on postoperative pain in 88 patients undergoing day case knee arthroscopy.

Methods: A prospective, double blind, randomized trial was performed. All patients received a standard general anesthetic. Patients in group A received $20 \mathrm{mg}$ tenoxicam made up to $40 \mathrm{ml}$ with normal saline intra-articularly (ia) and $2 \mathrm{ml}$ normal saline $i v$. Patients in group B received $40 \mathrm{ml}$ normal saline intra-articularly and $2 \mathrm{ml}, 20 \mathrm{mg}$ of tenoxicam, iv.

Results: Both groups of patients were similar with respect to age, weight, sex and tourniquet inflation time. Patients receiving ia tenoxicam had lower pain scores (at rest and upon movement) at 30,60, 120 and 180 min postoperatively $(0.8 \pm 0.2$ vs $2.5 \pm 0.2$ at rest and $1.24 \pm 0.2$ vs $3.4 \pm 0.2$ at movement at 60 min; $P<$ 0.000 I). Fewer patients required additional analgesia in the first four hours postoperatively ( $33 \%$ vs $84 \%$; $P<$ $0.00001)$ and the time to first analgesia $(23.7 \pm 11.2$ vs $9.4 \pm 0.6 ; P<0.02)$ was longer in those receiving io tenoxicam.

Conclusion: Intra-articular tenoxicam provides superior postoperative analgesia and reduces postoperative analgesic requirements compared with iv tenoxicam in patients undergoing day case knee arthroscopy.

Objectif : Les anti-inflammatoires non stéroïdiens sont des médicaments bien reconnus pour le soulagement de la douleur postopératoire. La présente étude avait pour but de comparer l'effet analgésique de $20 \mathrm{mg}$ de ténoxicam intra-articulaire à du ténoxicam intraveineux sur la douleur postopératoire chez 88 patients admis en chirurgie ambulatoire pour une arthroscopie du genou.

Méthode : On a procédé à un essai prospectif, randomisé et à double insu. Tous les patients ont reçu un anesthésique général standard. Les patients du groupe A ont reçu une injection intra-articulaire (ia) composée de $20 \mathrm{mg}$ de ténoxicam complété à $40 \mathrm{ml}$ par une solution salée et $2 \mathrm{ml}$ de solution salée $\mathrm{iv}$. Les patients du groupe B ont reçu $40 \mathrm{ml}$ de solution salée en injection intra-articulaire et $2 \mathrm{ml}, 20 \mathrm{mg}$ de ténoxicam, iv.

Résultats : Les deux groupes présentaient des caractéristiques semblables quant à l'âge, le poids, le sexe et le temps de gonflement du garrot. Les patients qui ont reçu du ténoxicam ia ont eu des scores de douleur plus bas (au repos et en mouvement) à 30,60, 120 et 180 min après l'intervention $(0,8 \pm 0,2$ vs $2,5 \pm 0,2$ au repos et $1,24 \pm 0,2$ vs 3,4 $\pm 0,2$ en mouvement à $60 \mathrm{~min} ; P<0,0001$ ). Moins de patients ont eu besoin d'analgésie supplémentaire pendant les quatre premières heures postopératoires (33\% vs $84 \% ; P<0,00001$ ) et le temps écoulé avant la première analgésie $(23,7 \pm 11,2$ vs $9,4 \pm 0,6 P<0,02)$ a été plus long pour les patients qui ont reçu du ténoxicam ia.

Conclusion : Le ténoxicam intra-articulaire, comparé au ténoxicam iv, fournit une analgésie postopératoire supérieure et réduit les besoins analgésiques postopératoires chez des patients qui subissent une arthroscopie du genou en chirurgie ambulatoire.

From the Departments of Anaesthesia and Surgery, ${ }^{*}$ Cappagh Orthopedic Hospital, Finglas, Dublin 11, Ireland.

Address correspondence to: Dr. Sallyann Colbert, Department of Anaesthesia, Mater Misericordiae Hospital, Eccles Street, Dublin 7 Ireland.

Accepted for publication March 31, 1999 
A DEQUATE postoperative analgesia is an essential requirement for day case surgery. Different analgesic agents for day case arthroscopy have been studied but an ideal agent is difficult to identify. It should be active upon cessation of surgery, have a prolonged duration of action, be easy to administer and be without serious side effects.

Many studies have focused on the benefits of local application of different agents. The use of intra-articular (ia) steroids, opioids, local anesthetic agents and a combination of opioids and local anesthetic agents have been shown to achieve clinical benefits with respect to postoperative analgesia in many studies but others have failed to demonstrate a beneficial use and their use is controversial. ${ }^{1-6}$ The advantage of the intraarticular route of drug administration is that it has therapeutic benefit with fewer systemic side effects.

Intra-articular administration of nonsteroidal antiinflammatory drugs (NSAIDs) has received little attention. Non Steroidal Anti-Inflammatory Drugs are effective in reducing postoperative pain. ${ }^{7}$ Tenoxicam is a potent analgesic and anti-inflammatory agent and has an established efficacy in postoperative pain relief. ${ }^{8,9}$ In view of its long half-life (60-80 $\mathrm{hr}$ ), once daily administration is sufficient. The parenteral formulation of tenoxicam has an aqueous base, without an organic stabilizer and since the solvent for injection is distilled water, this formulation offers the potential for intra-articular administration. Other non-steroidal drugs are unsuitable due to the solvents employed which cause problems with local tolerability. Tenoxicam has also been demonstrated to concentrate in the synovium rather than in the cartilage. ${ }^{10}$

The purpose of this study was to compare the benefits of intra-articular tenoxicam, $20 \mathrm{mg}$, and $20 \mathrm{mg}$ tenoxicam $i v$ on postoperative pain relief and further analgesic requirements in patients undergoing day case knee arthroscopy.

\section{Materials and methods}

A prospective randomized double blind trial was undertaken. Following informed written consent, Irish Medicines Board and local ethical committee approval, patients undergoing diagnostic day case knee arthroscopy were included in the study. Exclusion criteria were patients who were already receiving NSAID treatment or those who had evidence of severe cardiovascular, respiratory, metabolic or neurological disease. Patients in whom NSAIDs were contraindicated, i.e. those suffering from peptic ulcer disease, gastrointestinal bleeding, gastritis or renal failure were also excluded from the study.
Patients were randomly allocated into one of two groups, using a table of random numbers. Ninety patients between 18 - $65 \mathrm{yr}$ who were ASA I - II were enrolled into this prospective randomized trial. A study proforma was completed giving demographic, perioperative and postoperative details.

No premedication was administered. Intraoperative monitoring consisted of inspired oxygen concentration, ECG, oxygen saturation, $\mathrm{P}_{\mathrm{ET}} \mathrm{CO}_{2}$ and non-invasive blood pressure. The anesthetic technique for both groups was standardized. Anesthesia was induced with 2.5-3 $\mathrm{mg} \cdot \mathrm{kg}^{-1}$ propofol and $1 \mu \mathrm{gg} \cdot \mathrm{kg}^{-1}$ fentanyl. Patients breathed spontaneously via a laryngeal mask airway, anesthesia being maintained by isoflurane and nitrous oxide $66 \%$ in oxygen.

At the conclusion of surgery, $10 \mathrm{~min}$ before deflation of the tourniquet, the surgeon injected the drug or placebo into the knee joint through the arthroscope. Patients in group A received $20 \mathrm{mg}$ tenoxicam made up to $40 \mathrm{ml}$ with normal saline intra-articularly and $2 \mathrm{ml}$ normal saline iv administered by the anesthesiologist at the same time. Patients allocated to group B received $40 \mathrm{ml}$ normal saline intra-articularly and $20 \mathrm{mg}, 2 \mathrm{ml}$, tenoxicam $i v$.

Postoperative pain was assessed via a $10 \mathrm{~cm}$ visual analogue scale (VAS) ranging from no pain $(0 \mathrm{~cm})$ to unbearable pain $(10 \mathrm{~cm})$. These were recorded at rest and upon movement (the patient was asked to flex the knee joint $45^{\circ}$ ). The use of these measures was explained to patients before surgery. The scores were obtained by an independent investigator with no knowledge as to which group the patient belonged. The VAS scores were assessed at 30,60, 120, and $240 \mathrm{~min}$ postoperatively. Supplemental postoperative analgesia consisting of 0.5 $\mathrm{mg} \cdot \mathrm{kg}^{-1}$ meperidine iv or $500 \mathrm{mg}$ acetaminophen tablets up to eight tablets a day po was available on request. Time to first requesting analgesia and all analgesic agents administered to the patient in the first four hours postoperatively were recorded.

Statistical analysis was performed using standard non parametric statistics i.e., the Mann Whitney U test and Chi square test with significance assumed at the $5 \%$ level.

\section{Results}

Ninety patients were enrolled in the study and 88 completed the study. Two patients were excluded because they required admission; one patient has received $i v$ tenoxicam and was admitted following an episode of an unexplained arrhythmia postoperatively and the second because of prolonged nausea and vomiting. No patient in this study required admission because of poor pain control. 
TABLE I Detailing the demographic criteria and analgesic requirements in the two groups.

\begin{tabular}{|c|c|c|c|}
\hline Variable & Group $A$ & Group $B$ & $P$ \\
\hline $\mathbf{n}$ & 45 & 43 & \\
\hline Age $(y r)$ & $31.1 \pm 1.1$ & $33.5 \pm 1.0$ & ns \\
\hline Sex $(n$, male $\%)$ & $23(51 \%)$ & $21(49 \%)$ & ns \\
\hline Weight (kg) & $72.1 \pm 1.4$ & $70.9 \pm 1.3$ & ns \\
\hline Tourniquet Time (min) & $30.9 \pm 0.9$ & $32.2 \pm 0.7$ & ns \\
\hline $\begin{array}{l}\text { Additional analgesia } \\
\text { (n first } 4 \mathrm{hr} \text { ) }\end{array}$ & $15(33 \%)$ & $36(84 \%)$ & $<0.00001$ \\
\hline $\begin{array}{l}\text { Meperidine use } \\
\text { (no. of patients) }\end{array}$ & 2 & 16 & $<0.0001$ \\
\hline $\begin{array}{l}\text { Acetaminophen use } \\
\text { (no. of patients) }\end{array}$ & 13 & 20 & ns \\
\hline Time first analgesia (min) & $23.7 \pm 11.2$ & $9.4 \pm 0.6$ & 0.02 \\
\hline
\end{tabular}

Group A = Intra-articular tenoxicam. Group B = Intravenous tenoxicam.

Values expressed as mean \pm SEM or as number (Percent), ns $=$ not significant.

TABLE II Pain scores in each group at each of the time periods

\begin{tabular}{llll}
\hline Time period & Group $A$ & Group $B$ & $P$ \\
\hline Number & 45 & 43 & \\
Pain (R) at $30 \mathrm{~min}$ & $1.4 \pm 0.2$ & $2.8 \pm 0.2$ & $<0.0001$ \\
Pain (M) at $30 \mathrm{~min}$ & $2.0 \pm 0.2$ & $3.9 \pm 0.2$ & $<0.0001$ \\
Pain (R) at $60 \mathrm{~min}$ & $0.8 \pm 0.2$ & $2.5 \pm 0.2$ & $<0.0001$ \\
Pain (M) at $60 \mathrm{~min}$ & $1.24 \pm 0.2$ & $3.4 \pm 0.2$ & $<0.0001$ \\
Pain (R) at $120 \mathrm{~min}$ & $0.5 \pm 0.1$ & $1.6 \pm 0.2$ & $<0.0001$ \\
Pain (M) at $120 \mathrm{~min}$ & $0.7 \pm 0.2$ & $2.2 \pm 0.2$ & $<0.0001$ \\
Pain (R) at $180 \mathrm{~min}$ & $0.1 \pm 0.1$ & $0.6 \pm 0.1$ & $=0.001$ \\
Pain (M) at $180 \mathrm{~min}$ & $0.2 \pm 0.1$ & $0.9 \pm 0.2$ & $=0.001$ \\
Pain (R) at $240 \mathrm{~min}$ & $0.0 \pm 0.0$ & $0.1 \pm 0.0$ & NS \\
Pain (M) at $240 \mathrm{~min}$ & $0.0 \pm 0.0$ & $0.1 \pm 0.0$ & NS \\
\hline
\end{tabular}

Group A = Intraarticular tenoxicam. Group B = Intravenous tenoxicam.

Values expressed as mean $\pm S E M$. $R=$ at rest, $M=$ upon movement, NS = not significant.

There were 45 patients in group $\mathrm{A}(20 \mathrm{mg}$ tenoxicam $i a$ and $2 \mathrm{ml}$ normal saline $i p$ ) and 43 patients in group B ( $40 \mathrm{ml}$ normal saline iv and $20 \mathrm{mg}$ tenoxicam iv). Forty three of the patients were male.

There was no difference between the two groups with regard to age, sex, weight or tourniquet time (Table I). Differences were observed in the pain scores (at rest and upon movement) at 30,60, 120,180 min but not at $240 \mathrm{~min}$ postoperatively (Table II). There were differences between the two groups with respect to the number of patients requiring additional analgesia in the first four hours postoperatively, specifically meperidine, and the time to first analgesia (Table I).
The mean \pm SEM dose of meperidine consumed was $25 \pm 0.0 \mathrm{mg}$ in group $\mathrm{A}$ and $31.2 \pm 2.8 \mathrm{mg}$ in group B. Any patients who received acetaminophen had a $500 \mathrm{mg}$ dose administered and the mean was $500 \mathrm{mg}$ in both groups.

\section{Discussion}

In the present study examining Intra-articular $v s$ intravenous tenoxicam, the local intra-articular route had benefits in terms of decreased postoperative pain scores both at rest and upon movement. In addition, the further analgesic requirements in the group receiving intra-articular tenoxicam were less than in those receiving systemic tenoxicam and the time to first additional postoperative analgesia was also prolonged.

Papathanassiou examined intra-articular injection of $20 \mathrm{mg}$ tenoxicam in 28 patients with degenerative osteoarthritis of the knee joint ${ }^{11}$ and demonstrated a $40 \%$ reduction in analgesia consumption and a $60 \%$ increase in joint movements lasting up to two months after a single injection. Two patients reported a slight allergic reaction: otherwise no other side effects were detected. Elhakim et al. evaluated the postoperative analgesic effects of $i a$ tenoxicam compared with $i v$ tenoxicam in 60 patients undergoing day case arthroscopy ${ }^{12}$ and showed lower pain scores (at rest and upon movement) and reduced analgesic requirements postoperatively in the group who received in tenoxicam. Similar results were obtained in the present study. There was a reduction in the number of patients requiring meperidine in the $i a$ group than in the iv group. No difference was observed for acetaminophen consumption.

However, in contrast to these results Cook $e t$ al. examined 63 patients undergoing day case knee arthroscopy and compared $i a$ tenoxicam with $i a$ bupivacaine, and ia placebo $^{13}$ but failed to demonstrate any benefit in terms of pain scores following the use of tenoxicam or bupivacaine over placebo. Monahan et $a l$. also found no benefit following the use of $i a$ ketorolac $v$ s ia bupivaciane in 40 patients undergoing day case knee arthroscopy. ${ }^{14}$

Reuben et al. evaluated ketorolac in 80 patients undergoing day case arthroscopy ${ }^{15}$ and divided the patients into four groups; Group $1 i a$ ketorolac; Group $2 i a$ ketorolac and $i a$ bupivacaine; Group 3 ia bupivacaine and iv ketorolac and Group 4 ia bupivacaine. Those receiving $i a$ ketolorac combined with $i a$ bupivacaine had better pain scores and consumed less analgesia postoperatively. In a second study, Reuben $e t$ al. ${ }^{16}$ examined patients undergoing arthroscopic meniscus repair and concluded that intra-articular ketorolac improves pain scores in this patient population. 
The intra-articular route of analgesic administration has been examined in a number of studies. Intra-articular opioids have been studied and encouraging results have been found with reduced pain scores and reduced postoperative analgesic consumption after knee surgery. ${ }^{2,17,18}$ However, these findings have not been demonstrated in other studies. ${ }^{19,20}$ Intra-articular administration of local anesthetic agents has also proved controversial. Geutjens $e t$ al. ${ }^{21}$ found a beneficial effect following intra-articular bupivacaine in patients undergoing day case arthroscopy. Henderson $e t$ al. ${ }^{22}$, in a similar study, found no benefit. A combination of agents has also been examined. McSwiney et al..$^{5}$ divided patients undergoing arthroscopy into four groups; Group 1 received normal saline, Group 2 bupivacaine , Group 3 morphine and Group 4 bupivacaine and morphine combined. All agents were administered intraarticularly. Group 4 patients had lower pain scores postoperatively. Similar results were produced by Boden et al. $^{23}$ Other studies have examined the use of intraarticular steroids. Excellent analgesia can be achieved but repeated use may cause problems with joint destruction. $1,17,24$

Experimental studies have implicated prostaglandin $\mathrm{E}_{2}$, produced by synoviocytes, in joint inflammation. ${ }^{25,26}$ NSAIDs inhibit prostaglandin synthesis and are potent anti-inflammatory agents. Many NSAIDs are currently available but only a few are suitable for Intraarticular administration because of formulation. In addition several NSAIDs have been shown to inhibit chondrocyte biosynthesis and have been implicated in cartilage destruction in vitro and in vivo. The aqueous based parenteral formulation of tenoxicam make this NSAID suitable for intra- articular administration. In contrast to other NSAIDs, tenoxicam has a chondroprotective effect in human cartilage in vitro and may have beneficial effects. ${ }^{27}$

The present study demonstrated considerable benefits with $i a$ tenoxicam compared with the same dose administered $i v$ in patients undergoing day case knee arthroscopy. The cost of $20 \mathrm{mg}$ tenoxicam was $\$ 2.23$ and was the same in both arms of the study as the same formulary was employed. Intra-articular administration of tenoxicam should be considered in all patients undergoing day case arthroscopy, who do not have contraindications to NSAID use.

\section{Acknowledgments}

We would like to thank the Cappagh Hospital Trust for financial support given. We would also like to thank the Anesthetic and Recovery Room nurses for their help in carrying out this study.

\section{References}

1 Boyle AC. Local injection of steroids - Part 11 Intraarticular injections. Rheumatic Diseases - Collected reports 1959-1983. London: The Arthritis and Rheumatism Council for Research 1983: 191-3.

2 Stein C, Comisel K, Haimerl E, et al. Analgesic effect of intraarticular morphine after arthroscopic knee surgery. N Engl J Med 1991; 325: 1123-6.

3 Joshi GP, McCarroll SM, Cooney CM, Blunnie WP, O'Brien TM, Lawrence AJ. Intra-articular morphine for pain relief after knee arthroscopy. J Bone Joint Surg (Lond) 1992; 74B: 749-51.

4 Lyons B, Lohan D, Flynn CG, Joshi GP, O'Brien TM, McCarroll $M$. Intraarticular analgesia for arthroscopic meniscectomy. $\mathrm{Br}$ J Anaesth 1995; 75: 552-5.

5 McSwiney MM, Joshi GP, Kenny P, McCarroll SM. Analgesia following arthroscopic knee surgery. A controlled study of intraarticular morphine, bupivacaine or both combined. Anesth Intensive Care 1993; 21: 201-3.

6 Khoury GF, Chen $A C N$, Garland DE, Stein C. Intraarticuar morphine, bupivacaine, and morphine/ bupivacaine for pain control after knee videoarthroscopy. Anesthesiology 1992; 77; 263-6.

7 Dabl JB, Keblet $H$. Non steroidal anti-inflammatory drugs: rationale for use in severe postoperative pain. $\mathrm{Br}$ J Anaesth 1991; 66: 703-12.

8 Liaw W-J, Day $\Upsilon$-J, Wang J-J, Ho S-T. Intravenous tenoxicam reduces dose and side effects of PCA morphine in patients after thoracic endoscopic sympathectomy. Acta Anaesthesiol Sin 1995; 33: 73-7.

9 Merry AF, Wardall GJ, Cameron RJ, Peskett MJ, Wild $C J$. Prospective, controlled, double-blind study of IV tenoxicam for analgesia after thoracotomy. $\mathrm{Br} \mathrm{J}$ Anaesth 1992; 69: 92-4.

10 Bannwarth $B$, Netter $P$, Lapicque $F$, et al. Tenoxicam concentrations in synovium and joint cartilage in humans. Agents Actions Suppl 1991; 32: 295-8.

11 Papathanassiou NP. Intra-articular use of tenoxicam in degenerative osteoarthritis of the knee joint. J Int Med Research 1994; 22: 332-7.

12 Elbakim $M$, Fatby $A$, Elkott $M$, Said MM. Intra-articular tenoxicam relieves post-arthroscopy pain. Acta Anaesthesiol Scand 1996; 40: 1223-6.

13 Cook TM, Tuckey JP, Nolan JP. Analgesia after day-case knee arthroscopy: double blind study of intraarticular tenoxicam, intraarticular bupivacaine and placebo. $\mathrm{Br} \mathrm{J}$ Anaesth 1997; 78: 163-8.

14 Monaban SJ, Johnson CJ, Downing JE, Fontenot KJ, Bubrman WC. Post arthroscopy analgesia with intraarticular ketorolac. Anesthesiology 1992; 77: A854.

15 Reuben SS, Connelly NR. Postoperative analgesia for outpatient arthroscopic knee surgery with intraarticular bupivacaine and ketorolac. Anesth Analg 1995; 80: 1154-7. 
16 Reuben SS, Connelly NR. Postarthroscopic meniscus repair analgesia with intraarticular ketorolac or morphine. Anesth Analg 1996; 82: 1036-9.

17 Stein C, Millan MJ, Yassouridis A, Herz A. Antinociceptive effects of $\mu$ - and - agonists in inflammation are enhanced by a peripheral opioid receptorspecific mechanism. Eur J Pharmacol 1988; 155 : 255-64.

18 Kboury GF, Stein C, Garland DE. Intra-articular morphine for pain after knee arthroscopy (Letter). Lancet 1990 336: 874.

19 Björnsson A, Gupta A, Vegfors $M$, Lennmarken $C$, Sjöberg $F$. Intraarticular morphine for postoperative analgesia following knee arthroscopy. Reg Anesth 1994; 19: 104-8.

20 Laurent SC, Nolan JP, Pozo $J$, Jones $C J$. Addition of morphine to intra-articular bupivacaine does not improve analgesia after day-case arthroscopy. $\mathrm{Br}$ J Anaesth 1994; 72: 170-3.

21 Geutjens $G$, Hambidge JE. Analgesic effects of intraarticular bupivacaine after day-case arthroscopy. Arthroscopy 1994; 10: 299-300.

22 Henderson RC, Campion ER, DeMasi RA, Taft TN. Postarthroscopy analgesia with bupivacaine. A prospective, randomized, blinded evaluation. Am J Sports Med 1990; 18: 614-7.

23 Boden BP, Fassler S, Cooper S, Marchetto PA, Moyer RA. Analgesic effect of intraarticular morphine, bupivacaine, and morphine/bupivacaine after arthroscopic knee surgery. Arthroscopy 1994; 10: 104-7.

24 Grillet B, Dequeker J. Intraarticular steroid injection. A risk-benefit assessment. Drug Safety 1990; 5: 205-11.

25 Levine JD, Clarke R, Devor M, Helms C, Moskowitz $M A$, Basbaum $A I$. Intraneuronal substance $\mathrm{P}$ contributes to the severity of experimental arthritis. Science 1984; 226: 547-9.

26 Lotz $M$, Carson DA, Vaughan JH. Substance P activation of rheumatoid synoviocytes: neural pathway in pathogenesis of arthritis. Science 1987; 235: 893-5.

27 Vignon E, Mathieu P, Louisot P, Richard M. In vitro effect of nonsteroidal antiinflammatory drugs on proteoglycanase and collagenase activity in human osteoarthritic cartilage. Arthritis Rheum 1991; 34: 1332-5. 